\title{
INTELLIGENT ORGANIZATIONS IN DIGITAL AGE - CASE STUDY OF SMES IN POLAND
}

\author{
Piotr Adamczewski \\ WSB University, Institute of Management, Poznan, Poland
}

CMESTE

JEL Category: A23

\begin{abstract}
Business in the 21st century is being redefined by a data-driven revolution. Small and medium enterprises (SMEs) play an essential role in the global economic growth. The share of the Polish SME sector in GNP has been at $48 \%$ for years now. This sector has been also among the most dynamically developing and computerizing areas in the Polish economy. ICT (Information and Communication Technology) systems create the foundation of modern economic organizations in the times of digital transformation. This applies in particular to advanced ICT infrastructure, which is the condition sine qua non for the effective knowledge management. The objective of this article is to discuss organizational and technological aspects within the modern knowledge management using ICT called SMAC (Social, Mobility, Analytics, Cloud), being at present the canon of ICT support in this respect. The analysis has been illustrated with findings of research carried out by the author in 2014-17 in selected SMEs from Mazowieckie and Wielkopolskie provinces.
\end{abstract}

Keywords: ICT, intelligent organization, SMAC, knowledge management, SME.

\section{INTRODUCTION}

The global economy evolves into a "knowledgebased economy", where the market success of enterprises more and more depends on efficient knowledge management, that is on the acquisition, generation, distribution, and application of knowledge within organizations. The strategically important nature of knowledge results firstly from the fact that it is harder to imitate and substitute when compared with material resources, and secondly from the fact that it is more flexible, i.e. more useful for the creation or improvement of various elements of the enterprise's offer. Knowledge is currently

Address of the author:

Piotr Adamczewski

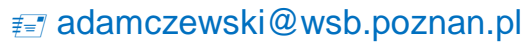

perceived as a strategic enterprise resource and as such, it should be subject to constant identification, measurement, acquisition, development, utilization, and protection. In other words, it should be appropriately managed. The operation of globalized and modern organizations requires the continuous adaptation of management methods and development strategies to new economic conditions. This is particularly important in the process of digital transformation, which has been transforming all sectors for several years now. This applies in particular to the issues of knowledge management in economic organizations, which can be analyzed in the area of organizational structures, business processes, personnel, organizational structure as well as ICT that supports management. 
Similarly, to the other EU Member States, the largest share of GNP in Poland is generated by the sector of small and medium enterprises. The competitive potential of SMEs operating in Poland is high (very high price competitiveness, high competitiveness in terms of product and service quality, and improving innovation competitiveness). However, to fully utilize such potential, SMEs must operate based on state-ofthe-art ICT solutions. Due to differences between SMEs and large organizations and international corporations, a question arises as to the extent to which the SME sector can implement advanced ICT solutions effectively in the period of digital transformation? What factors determine decisions taken in this respect, and what implementation barriers occur?

This article is aimed at presenting the latest condition of digitalization and development tendencies in supporting the SME sector with SMAC solutions (Social, Mobility, Analytics, Cloud), which is a sine qua non condition of enterprises from this sector to operate in a modern way and to take part in the process of digital transformation. According to research by Cisco Global Cloud Index, half of the global population will have access to the Internet in 2018, and more than $53 \%$ of them will use tools for storing data in the cloud (Cisco, 2016). ICT implementation in every organization depends on numerous factors, mostly organizational, human, and technical, but also on the needs of the management, which can be more or less conscious. Unlike large organizations, where the implementation of advanced SMAC is perceived positively, it seems that an opposite approach can occur to this trend in the SME sector. Hence, the objective of the research has been defined to test the readiness of Polish SMEs to implement and use systems within the so-called 3rd ICT platform. In order to fulfill the objective, the following research hypotheses have been formulated:

- elements of SMAC solutions are used on an increasing scale in SMEs,

- SME management pays growing attention to the implementation of SMAC systems.

The analyses are illustrated with survey results and direct observations of the author from 20142017 in selected 120 SMEs from Mazowieckie and Wielkopolskie provinces, Poland, with reference to the general development trends in the studied area. The survey sample was made up of micro $(9 \%)$, small $(56 \%)$ and medium-sized enterprises $(35 \%)$. Surveyed companies represent a wide range of industries: retail and wholesale trade, discrete and process manufacturing, transport, HoReCa, utilities, finance, construction, telecommunication, and ICT.

\section{INTELLIGENT ORGANIZATIONS IN TURBULENT ECONOMY}

The dynamics of market changes and the high level of turbulence in the business environment make modern economic organizations face the challenge of continuous improvement in their operational methods and development. In practice, it implies the necessity to use modern ICT solutions in knowledge management, which enable to support business processes within the acquisition and reinforcement of business's competitive advantages. Within the evolution of the information society towards the knowledge society, it boils down to the treatment of modern organizations as intelligent organizations. An intelligent organization is one whose business philosophy is based on knowledge management (Waltz, 2003). This term became popular in the 1990s owing to the growing ICT development, the dynamically changing economic environment, and the increasing market competitiveness. An intelligent organization is one that learns and has the capacity to create, acquire, organize, and share knowledge and use it in order to raise the efficiency of its operation and increase competitiveness on the global market. The idea of such an organization is based on the systemic approach to organization, i.e. its treatment as a complex organism founded on existing structures and executed processes, focusing on the role of knowledge. In that approach, which is called 'the fifth discipline' by P. Senge, owing to knowledge and suitable tools all elements of an organization and its personnel can collaborate in order to achieve set objectives (Senge, 2002). Thanks to that, the whole organization operates as an intelligent and successful organism in the competitive environment. This explains the mutual relationships between methods of fulfilling targets, their understanding, methods of solving problems as well as internal and external communication. 
The most important characteristics of an intelligent organization include, among other (Groesser, 2012), (Schwaninger, 2009):

- the fast and flexible operation,

- the ability to monitor the environment,

- the capacity to diagnose early market signals and to react to changes in the environment, and

- $\quad$ the ability to implement new knowledge-based solutions and achieve economic benefits therefrom.

The growing volume of information used in an intelligent organization is accompanied by its increasing importance. Peter Drucker indicated already that traditional factors of production, such as growth, labor, and capital, are losing their importance in favor of a key resource, namely knowledge applied in the creative operation of an organization. It constitutes intangible resources that are related to human actions, whose use may be the basis for gaining a competitive advantage (Schwaninger, 2009). Knowledge has to be treated as information embedded in the context of an organization and a skill to use it effectively in the organizational activity. It means that knowledge resources are data about its customers, products, processes, environment, etc. in a formalized form (documents, databases) and in non-codified forms (knowledge of staff).

In the practical dimension, the effective collaboration of such elements means the necessity to use advanced ICT solutions. Technical, technological, and organizational innovations, which have appeared in recent years, are all utilized. They encompass almost all areas of a modern organization operation, starting from means of transport and equipment, through organization and material and raw material flow management, to the development of system structures that implement business processes, i.e. within logistics systems that are the essence of modern management based on e-logistics (Adamczewski, 2017).

\section{TRENDS OF ICT SOLUTIONS ON INTELLIGENT ORGANIZATIONS}

Digital business blurs the physical and virtual worlds in a way that transforms business designs, industries, markets, and organizations. The continuing digital business evolution exploits emerging and strategic technologies to integrate the physical and digital worlds and create entirely new business models. The future will be defined by smart devices delivering increasingly insightful digital services everywhere. We call this mesh of interconnected people, devices, content, and services the intelligent digital mesh. It's enabled by digital business platforms delivering a rich intelligent set of services to support digital business (Panneta, 2017):

- artificial intelligence (Al) delivers value to every industry, enabling new business models. It does so by supporting key initiatives such as customer engagement, digital production, smart cities, self-driving cars, risk management, computer vision and speech recognition;

- as people, places, processes and "things" become increasingly digitalized, they will be represented by digital twins. This will provide fertile ground for new event-driven business processes and digitally enabled business models and ecosystems;

- the way we interact with technology will undergo a radical transformation over the next five to 10 years. Conversational platforms, augmented reality, virtual reality and mixed reality will provide more natural and immersive interactions with the digital world;

- a digital business is event-centric, which means it must be continuously sensing and adapting. The same applies to the security and risk infrastructure that supports it, which must focus on deceiving potential intruders and predicting security events.

Enterprise architecture (EA) and technology innovation leaders using EA to master emerging and strategic trends must:

devise new business scenarios using $\mathrm{Al}$ as the enabler for new business designs. Do so by engaging, educating and ideating with senior business leaders about their strategically relevant priorities;

- create a more natural and immersive user experience by deploying, where effective, conversational platforms and virtual, augmented and mixed reality;

- $\quad$ support the Internet of Things (IOT) initiatives by developing and prioritizing targeted, highvalue business cases to build digital twins and 
exploit cloud and edge computing synergistically;

- adopt a strategic approach to security and risk that continuously adapts based on risk and trust. Do so by communicating requirements to developers, achieving a DevSecOps environment.

As an enterprise architecture or technology innovation leader seeking to exploit the intelligent digital mesh, you must respond to the disruptive technology trends driving this future. Top 10 strategic technology trends include three groupings of complementary trends:

- the intelligent theme explores how $\mathrm{Al}$ is seeping into virtually every existing technology and creating entirely new technology categories;

- the digital theme focuses on blending the digital and physical worlds to create a natural and immersive, digitally enhanced experience. As the amount of data that things produce increases exponentially, compute power shifts to the edge to process stream data and send summary data to central systems. Digital trends, along with opportunities enabled by $\mathrm{Al}$, are driving the next generation of digital business and the creation of digital business ecosystems;

- the mesh theme refers to exploiting connections between an expanding set of people and businesses - as well as devices, content, and services - to deliver digital business outcomes. The mesh demands new capabilities that reduce friction, provide indepth security and respond to events across these connections.

Top 10 list highlights strategic trends that aren't yet widely recognized but have broad industry impact and significant potential for disruption. Through 2022, technologies related to these trends will reach a level of maturity that crosses a critical tipping point. And they'll experience significant changes (Panneta, 2017).

Trend No. 1: Al Foundation - Interest in $\mathrm{Al}$ is growing, as shown by an increase of more than $500 \%$ in the number of inquiry calls from Gartner clients about topics related to $\mathrm{Al}$ in the past year. A 2017 Gartner survey found that 59\% of organizations are still gathering information to build their Al strategies, while the rest have already made progress in piloting or adopting $\mathrm{Al}$ solutions. Furthermore, the market indicates strong investment in startups selling $\mathrm{Al}$ technologies. Creating systems that learn, adapt and potentially act autonomously will be a major battleground for technology vendors through at least 2020. The ability to use Al to enhance decision making, reinvent business models and ecosystems, and remake the customer experience will drive the payoff for digital initiatives through 2025. The Al foundation consists of numerous technologies and techniques that have grown over many years. These include expert systems, decision trees, linear regression and neural networks. The level of capability has grown steadily. This is the result of (Li, 2015), (Marz, 2015):

- ever-more advanced algorithms using supervised, unsupervised and reinforcementlearning techniques,

- the availability of massive amounts of data to feed machine learning,

- hardware advances (such as servers based on graphics processing units) delivering massive compute infrastructure to process the huge amount of data and sophisticated algorithms.

Advanced machine learning in the form of deep learning has further extended the problem domains that $\mathrm{Al}$ addresses. Examine the wide variety of Al-related techniques and exploit them as needed.

Trend No. 2: Intelligent Apps and Analytics Organizations are applying Al techniques to create new app categories (such as virtual customer assistants [VCAs]) and improve traditional applications (such as worker performance analysis, sales and marketing, and security). Intelligent apps have the potential to transform the nature of work and the structure of the workplace. When building or buying an Alpowered app, consider where its Al impact will be. It's useful to focus on three target domains when exploring how and where to exploit Al:

- Analytics: Al can be used to create more predictive and prescriptive analytics that can then be presented to users for further evaluation or plugged into a process to drive autonomous action. $\mathrm{Al}$ is also being used for augmented analytics; 
- Process: Al can drive more intelligent actions by an application. For example, you can use Al for intelligent invoice matching or analysis of email documents to improve service flow. In the future, this can be extended further to identify patterns of work, from which process models can be built and executed;

- User Experience: Natural-language processing used to create VPAs is one application of $\mathrm{Al}$ to the user experience. Further examples include facial recognition and other $\mathrm{Al}$ applications for understanding user emotions, context or intent, and predicting user needs.

During the next few years, virtually every app, application, and service will incorporate some level of Al. Some of these apps will be obvious intelligent apps that couldn't exist without $\mathrm{Al}$ and machine learning. Others will be unobtrusive users of $\mathrm{Al}$ that provide intelligence behind the scenes.

Trend No. 3: Intelligent Things - Intelligent things are physical things that go beyond the execution of rigid programming models and exploit $\mathrm{Al}$ to deliver advanced behaviors that interact more naturally with their surroundings and with people. $\mathrm{Al}$ is driving advances for new intelligent things, such as autonomous vehicles, robots and drones, and delivering enhanced capability to many existing things, such as loT-connected consumer and industrial systems. Intelligent things are either semiautonomous or fully autonomous. The word "autonomous," when used to describe intelligent things, is subject to interpretation. When Gartner uses this term to describe intelligent things, we don't mean that these intelligent things have Alstyle freedom from external human control or influence.

Trend No. 4: Digital Twins - A digital twin is a digital representation of a real-world entity or system. The implementation of a digital twin is an encapsulated software object or model that mirrors a unique physical object. Data from multiple digital twins can be aggregated for a composite view across a number of real-world entities. The notion of a digital representation of real-world entities or systems is not new. You can argue that this was a central notion in the IT industry with the creation of computer-aided design representations of physical assets or profiles of individual customers. The difference in the latest iteration of digital twins is:

- the robustness of the models,

- digital twins' link to the real world, potentially in real time,

- the application of advanced big data analytics and $\mathrm{Al}$,

- the ability to interact with them and evaluate "what if" scenarios.

Digital twins in the context of loT projects are leading the interest in digital twins today. Welldesigned digital twins of assets could significantly improve enterprise decision making. They are linked to their real-world counterparts and are used to understand the state of the thing or system, respond to changes, improve operations, and add value. By 2020, we estimate there will be more than 20 billion connected sensors and endpoints, and digital twins will exist for potentially billions of things. Benefits will include asset optimization, competitive differentiation and improved user experience in nearly all industries.

Trend No. 5: Cloud to the Edge - Edge computing describes a computing topology in which information processing and content collection and delivery are placed closer to the sources and sinks of this information. Edge computing draws from the concepts of mesh networking and distributed processing. It tries to keep the traffic and processing local, with the goal being to reduce traffic and latency. As such, the notion of edge content delivery has existed for many years. The "where to process the data" pendulum has swung between highly centralized approaches (such as a mainframe or a centralized cloud service) and more decentralized approaches (such as PCs and mobile devices). Connectivity and latency challenges, bandwidth constraints and greater functionality embedded at the edge favor distributed deployment models. The advantages of processing power and low costs of operating at hyperscale, coupled with the complexity of managing and coordinating thousands of geographically separated endpoints, favor the centralized model.

Trend No. 6: Conversational Platforms Conversational platforms will drive the next big paradigm shift in how humans interact with the digital world. They will shift the model from technology-literate people to people-literate 
technology. The burden of translating intent will move from the user to the computer. The system takes a question or command from the user in natural language. It responds by executing a function, presenting content or asking for additional input.

Trend No. 7: Immersive Experience - While conversational platforms are changing the way in which people interact with the digital world, virtual reality (VR), augmented reality (AR) and mixed reality (MR) are changing the way in which people perceive the digital world. This combined shift in perception and interaction models leads to the future immersive user experience.

Trend No. 8: Blockchain - Blockchain is evolving from a digital currency infrastructure into a platform for digital transformation. Blockchain and other distributed-ledger technologies provide trust in untrusted environments, eliminating the need for a trusted central authority. In this research, we use the term "blockchain" as a generic term for all distributed-ledger technologies. Blockchain technologies offer a radical departure from the current centralized transaction and recordkeeping mechanisms. They can serve as a foundation of disruptive digital business for both established enterprises and startups. Blockchain will transform the exchange of value, much as HTTP/HTML transformed the exchange of webbased information.

Trend No. 9: Event-Driven Model - Business is always sensing, and ready to exploit new digital business moments. This is central to digital business. Business events reflect the discovery of notable states or state changes, such as the completion of a purchase order. Some business events, or combinations of events, constitute business moments - detected situations that call for specific business actions. The most significant business moments have implications for multiple parties (for example, separate applications, lines of business or partners).

Trend No. 10: Continuous Adaptive Risk and Trust - The intelligent digital mesh and related digital technology platforms and application architectures create an ever-more-complex world for security. The continuing evolution of the "hacker industry" and its use of increasingly sophisticated tools including the same advanced technologies available to enterprises - significantly raise the threat potential. Relying on perimeter defense and static rule-based security is inadequate and outdated. This is especially so as organizations exploit more mobile devices, cloud-based services, and open APIs for customers and partners to create business ecosystems. ICT leaders must focus on detecting and responding to threats, as well as more traditional measures, such as blocking, to prevent attacks and other abuses. At the same time, digital business will require more advanced access protection when systems and information are opened up to the digital mesh.

\section{ICT ECOSYSTEM IN A INTELLIGENT ORGANIZATION}

An intelligent organization, as an economic system that uses advanced ICT infrastructure in its internal organization and communication, including external communication, constitutes the essence of information society operation in business areas at present. In practice, it means that IT supports basic organizational structures and the application of the now economy concept in the online mode with (Adamczewski, 2017):

- the level of technical infrastructure (hardware),

- the level of system-communication infrastructure

- the level of application software, and

- the level of integrating business processes with external counterparties.

The dynamic development of ICT has led to the development of a new technological standard, namely SMAC systems, which enable to introduce new business models. They are based on four pillars (Perera, 2015):

1. Social - social networks are breaking barriers in information flow among people and are becoming platforms where the fast exchange of knowledge is becoming increasingly effective. Communication within social platforms is strongly replacing telephone or e-mail communication. This phenomenon is taking place in businesses as well, where the fast information exchange is of great importance. The use of social networks makes it possible to obtain a better customer interaction and, as a consequence, it becomes possible to react faster to problems and build a 
knowledge base according to preferences and behavior of users.

2. Mobile - mobile devices, such as smartphones, tablets, and notebooks, have become a basic working tool of a modern worker. They have also enhanced the opportunities to reach customers who use mobile phones and have become accustomed to e-shopping and using different types of services and applications anytime and anywhere. The growing popularity of mobile shopping has also forced enterprises to develop their online marketing and to provide customers with mobile channels. In such conditions, the presentation of an offer on mobile devices is the first step in achieving and maintaining a high position on the market.

3. Analytics - understanding the behavior and preferences of customers is one of the greatest advantages of using analytics. By using collected data that is analyzed with advanced algorithms, entrepreneurs can deduce how to earn loyalty from their customers, improve marketing campaigns, enhance product development processes, and render services that meet the preferences and requirements of customers. By learning tastes of their users, entrepreneurs can present content according to their expectations. The ultimate aim in using analytics in business is, therefore, taking right decisions based on updated and segregated information.

4. Cloud - the technology of a computing cloud offers tools that enable to collect and process data on network services effectively, which contributes to the efficient organization management. By using tools available in a cloud, it is possible to reduce operating costs of ICT systems, break down geographic barriers, and obtain access to data at any time and place. A cloud is a factor that puts other elements of the SMAC solution together.

There are numerous examples in the business practice proving that expectations and actual benefits from using ICT solutions do not tally. The cause of such an effect may be the shortage of the sufficient integration between implemented systems. A key to success in using the SMAC

\footnotetext{
1 The research was conducted in 2014-17 on a selected sample of 120 enterprises from the SME sector in Mazowieckie and Wielkopolskie provinces.
}

technology is to combine the four abovementioned technologies, which communicate among themselves, and to enable a synergy effect. None of the four technologies alone can give a full effect. The only synergy generated by all SMAC elements working together makes it possible to create a competitive advantage. So far, organizations have invested in mobility, cloud, business analytics, and using social media in business by creating independent, usually unintegrated solutions. Their combination within the third ICT platform allows to create new revenue-generating services, deepen relationships with customers, and improve the efficiency of organizational operation (Adamczewski, 2017).

According to IDC forecasts, in the next two years, $80 \%$ of global organizations will initiate projects of digital transformation in their knowledge management, to be based on SMAC systems, including as many as $50 \%$ of outlays spent on the 3rd ICT platform solutions (Gens, 2016). Research carried out by the author ${ }^{1}$ shows that the popularity of IT support in management processes in SMEs can be presented as follows (percentage of analyzed enterprises):

- finance and accounting - 87\%,

- human resources $-75 \%$,

- warehouse management $-63 \%$

- production management $-21 \%$,

- customer relationship management - 52\%,

- office work support - 96\% (including e-mail $98 \%)$, and

- procurement and sale process service $-64 \%$.

The analyzed enterprises use laptops and PCs in their day-to-day operations (99\% of indications). On average, they hold about 15 computers. The vast majority use both landlines and smartphones. Tablets are used in every third enterprise (36\%), with 4 tablets per firm on average. The abovementioned statistics are supplemented with the $48 \%$ ratio of using online messenger systems and taking advantage of the support provided by ICT freelancers at $59 \%$. SMEs usually do not use multi-layer data processing protections. Instead, they choose only basic anti-virus software $(90 \%)$. Every second enterprise $(53 \%)$ protects its data 
with a standardized policy of passwords that are set and managed by the management. On the other hand, less than half SMEs (48\%) encode their e-mails. Only one out of three firms use data backup (35\%), including as many as $88 \%$ having that process automated. Interestingly, backup is used to secure company data more often by entities that do not consider their ICT security to be of essential importance for their business.

The readiness of the studied entities to face the challenges of digital transformation is as follows:

- $22 \%$ of respondents answered positively, confirming the implementation of such tasks,

- $12 \%$ of respondents answered that such actions would be taken soon,

- $20 \%$ of responses indicated that such actions would be taken in the near future, and

- according to $46 \%$ of respondents, such actions were not being conducted and there were no such plans.

As regards the use of SMAC solutions, the statistics of the analyzed entities reflect the general global trend in this respect, i.e. (Choi, 2016), (Gajewski, 2016), (Gens, 2016):

- a cloud is used in $18 \%$ organizations ( $38 \%$ of the analyzed population plans to start using it),

- mobility is utilized in $29 \%$ of organizations (with $15 \%$ of analyzed population planning to launch it),

- analytics is applied by $9 \%$ of organizations (while $16 \%$ of the studied population have plans to start it), and

- social media are declared by as many as $45 \%$ of organizations already, and their use in the near future is declared by $55 \%$ of respondents.

The development trends of Polish intelligent organizations in the digital transformation is supplemented with the following declared initiatives (Corcoran, 2016), (Gajewski, 2016):

- office digitalization - $70 \%$,

- modernization of ICT infrastructure - $64 \%$,

- consolidation in ICT and advanced analytics $49 \%$,

- new mobile applications for personnel $-49 \%$,

- networking - $49 \%$, and

- mobile self-service applications for customers $-30 \%$
The fact of placing a customer in the center was confirmed by responses about catching up with the dynamically evolving needs of contemporary consumers. Moreover, half of the respondents indicated the necessity to follow the changing expectations of their customers, declaring it to be their top business priority. The continuous improvement of customer satisfaction level is possible mostly owing to investments in new ICT solutions. Only owing to them shopping can be comfortable, fast, and possible at any time and place, while customer service can be effective. It also means the new opportunities in acquiring knowledge about needs, behavior, and opinions of customers. In general, the above-mentioned study results show that Polish modern business organizations are becoming more confident in using advanced solutions of SMAC systems, to meet the challenges of digital transformation (Brunswicker, 2015).

The growing demands of intelligent organizations within the ICT support for knowledge management result in general from their operation in real-time (RTE - Real-Time Enterprise). Therefore, SMAC systems enable to raise the efficiency of management to a higher level by:

- reaching customers more effectively with mobile solutions,

- understanding customer needs better by using advanced analytics,

- communicating with customers more effectively via social media, and

- reducing data processing costs with cloud computing solutions.

\section{CONCLUSIONS}

Digital transformation requires not just the adoption of digital tools, but a complete change of mindset throughout the organization. Employees need to approach problems differently, communicate and collaborate differently, and measure success differently. Ultimately, an organization's operations, revenue model, and organizational structure will change. And to add to the complexity, the digital transformation will look different for every organization. Consequently, change management models are becoming an increasingly popular tool to help navigate and indeed drive the success of digital transformation projects. 
An active sector of SMEs in Poland is a prerequisite of a properly functioning market economy. This sector encompasses various enterprises. The dynamic economic changes and the evolution of business relationships devaluate traditional sources of competitive advantages in the SME sector, such as capital, infrastructure, access to outlets, and the quality of offered products and services. Modern enterprises that want to compete on the market effectively have to give priority to the flexibility of their organization and its ability to implement innovative business models and reorganize logistics processes. Examples of numerous Polish SMEs show that the vision of a business managed in a modern way has come into the dynamic phase of realization, while the effective knowledge management with advanced ICT solutions is growing to the role of paradigm. There is no doubt that reserves still present in the SME sector can be utilized, through supporting its operation with advanced ICT systems with the dominant role of SMAC solutions.

Statistics from the last years unequivocally confirm growing indicators of ICT solutions implementation in the sector of SMEs, which gives fair promise to Polish enterprises for their operations on global markets. Conducted research has confirmed research hypotheses. It shows that SMAC solutions are more and more common among small and medium enterprises while company management of the surveyed enterprises pays more and more attention to applying knowledge management systems. This stems from the conviction that in the times of digital transformation information technologies which support effective knowledge management not only allow to keep up with the rising competition but are an indispensable condition of market survival.

Nevertheless, it has to be remembered that the creation and development of such smart technologies have one basic aim for businesses, namely to accelerate the development pace and improve the quality of offered products and services, while reducing operating costs. Although it seems apparently simple, paradoxically innovation of Polish business organizations from the SME sector is burdened with the concern about the unknown. SMEs are afraid of investing in solutions that are not popular yet. Nevertheless, the strategic vision of the management in such organizations will determine the directions and pace of popularising modern and effective solutions in knowledge management, which may contribute to the improvement of their competitiveness on the global market.

According to the above analysis, the conditions of effective knowledge management in intelligent organizations have to be treated in a complementary way, so that ICT aspects, although very important, do not dominate the preparatory work or the operation of solutions in this respect. Equally important are so-called 'soft' conditions, which concern the strategy of organization's development, its organizational culture, and qualifications and motivation of personnel. One thing seems certain already - the period of digital transformation poses new challenges for Polish intelligent organizations in the area of knowledge management. If they rise to them, they can compete in global markets more effectively.

Polish SMEs as intelligent organizations with strong technological orientation appear to be well prepared for the challenges of the knowledgebased economy, where the quickness of access to knowledge and possibility of its utilization constitutes the key factor of competitiveness. The best evidence for that is the fact that intelligent organizations achieve much better economic results than the remaining organizations. It appears that, under current economic conditions where knowledge constitutes an increasingly important factor of competitiveness, assimilation of features and principles of functioning or intelligent organizations is inevitable. An important factor for stimulation of enterprises to adopt the features of intelligent organizations is represented by the dissemination of knowledge about intelligent organizations and promotion of the examples of good practices of enterprises that already operate under the intelligent organization formula. 


\section{WORKS CITED}

Adamczewski, P. (2017). Knowledge Management in Intelligent Organizations in the Times of the Digital Transformation - Findings of the Research on the Polish SME Sector. Research Journal, 75(4), 53-68.

Brunswicker S., \& Vanhaverbeke W. (2015). Open Innovation is Small and Medium-sized Enterprises (SME's): External Knowledge Sourcing Strategies and Internal Organizational Facilities. Journal of Small Business Management. 54(4), 1264-1288.

Choi, T.M., Chan, H.K., \& Yue, X. (2016). Recent Development in Big Data Analytics for business operations and risk management. IEEE Transactions on Cybernetics.

Cisco Global Cloud Index 2013-2018. (2016). San Jose: Cisco Systems Inc.

Corcoran P., \& Datta S. K. (2016). Mobile-edge Computing and the Internet of Things for Consumers: Extending Cloud Computing and Services to the Edge of the Network. IEEE Consumer Electronics Magazine, 5(4), 73-74.

Gajewski J., Paprocki W., \& Pieriegud J. (2016). Cyfryzacja gospodarki i społeczeństwa - szanse i wyzwania dla sektorów infrastrukturalnych. Gdansk: Instytut Badan nad Gospodarka Rynkowa.

Gens, F. (2016). Report IDC FutureScape 'Worldwide IT Industry 2016 Predictions: Leading Digital Transformation to Scale'. Retrieved from https://www.idc.com/getdoc.jsp?containerld=259850

Groesser, S.N., \& Zeier, R. (2012). Systematic Management for Intelligent Organizations. Berlin Heidelberg: Springer-Verlag.

Li, J., Tao, F., Cheng, Y. \& Zhao, L. (2015). Big data in product lifecycle management. The Intentional Journal of Advanced Manufacturing Technology, 81(1), 667-684.

Marz, N., \& Warren, J. (2015). Big Data: Principles and best practices of scalable realtime data systems. New York: Manning Publications.

Panneta, K. (2017, Oct 03). Gartner Top 10 Strategic Technology Trends for 2018. Retrieved from https://www.gartner.com/smarterwithgartner/gartner-top-10-strategic-technology-trends-for2018/

Perera, Ch., Ranjan, R., Wang, L., Khan, S., \& Zomaya, A. (2015). Privacy of Big Data in the Internet of Things Era. IEEE IT Professional Magazine, PrePrint (Internet of Anything). Retrieved from https://arxiv.org/pdf/1412.8339.

Schwaninger, M. (2009). Intelligent Organizations: Powerful Models for Systematic Management. Berlin Heidelberg: Springer-Verlag

Senge, P. (2002). Piata dyscyplina, teoria i praktyka organizacji uczacych sie. Krakow: Oficyna Ekonomiczna.

Waltz, E. (2003). Knowledge Management in the Intelligence Enterprise. Boston: Artech House.

Received for publication: 11.12.2017

Revision received: $\quad 22.01 .2018$

Accepted for publication: 07.06.2018

\section{How to cite this article?}

Style - APA Sixth Edition:

Adamczewski, P. (2018, July 15). Intelligent Organizations in Digital Age - Case Study of SMEs in Poland. (Z. Cekerevac, Ed.) MEST Journal, 6(2), 1-11. doi:10.12709/mest.06.06.02.01

Style - Chicago Sixteenth Edition:

Adamczewski, Piotr. 2018. "Intelligent Organizations in Digital Age - Case Study of SMEs in Poland." Edited by Zoran Cekerevac. MEST Journal (MESTE) 6 (2): 1-11. doi:10.12709/mest.06.06.02.01. 
Style - GOST Name Sort:

Adamczewski Piotr Intelligent Organizations in Digital Age - Case Study of SMEs in Poland [Journal] // MEST Journal / ed. Cekerevac Zoran. - Toronto : MESTE, July 15, 2018. - 2 : Vol. 6. - pp. 1-11.

Style - Harvard Anglia:

Adamczewski, P., 2018. Intelligent Organizations in Digital Age - Case Study of SMEs in Poland. MEST Journal, 15 July, 6(2), pp. 1-11.

Style - ISO 690 Numerical Reference:

Intelligent Organizations in Digital Age - Case Study of SMEs in Poland. Adamczewski, Piotr. [ed.] Zoran Cekerevac. 2, Toronto : MESTE, July 15, 2018, MEST Journal, Vol. 6, pp. 1-11. 